Article

\title{
Characteristics of Preliminary Breakdown Pulses in Positive Ground Flashes during Summer Thunderstorms in Sweden
}

\author{
Dalina Johari ${ }^{1,2, *}$, Vernon Cooray ${ }^{1}$, Mahbubur Rahman ${ }^{1}$, Pasan Hettiarachchi ${ }^{1}$ \\ and Mohd Muzafar Ismail ${ }^{1,3}$ \\ 1 Ångström Laboratory, Division of Electricity, Department of Engineering Sciences, Uppsala University, \\ Box 534, 75121 Uppsala, Sweden; vernon.cooray@angstrom.uu.se (V.C.); \\ mahbubur.rahman@angstrom.uu.se (M.R.); pasan.hettiarachchi@angstrom.uu.se (P.H.); \\ muzafar.ismail@angstrom.uu.se (M.M.I.) \\ 2 Faculty of Electrical Engineering, Centre for Power Electrical Engineering Studies, \\ Universiti Teknologi Mara, 40450 Shah Alam, Selangor, Malaysia \\ 3 Faculty of Electronics and Computer Engineering, Telecommunication Engineering Department, \\ Universiti Teknikal Malaysia Melaka, Hang Tuah Jaya, 76100 Durian Tunggal, Malacca, Malaysia \\ * Correspondence: dalina.johari@angstrom.uu.se; Tel.: +46-18-471-5908
}

Academic Editor: Farhad Rachidi

Received: 2 February 2016; Accepted: 3 March 2016; Published: 10 March 2016

\begin{abstract}
This paper presents the characteristics of the preliminary breakdown pulses (PBP) in 51 positive ground flashes recorded during 2014 summer thunderstorms in Sweden. Electric field measurements were conducted remotely using a broadband antenna system (up to $100 \mathrm{MHz}$ ) for a recording length of $1 \mathrm{~s}$ with $200 \mathrm{~ms}$ trigger time. In the analysis, PBP trains were observed in $86 \%$ of the cases. Based on the number of trains preceding the first return stroke, the PBP were classified into single and multiple train PBP. Characteristics of the first PBP train were determined and based on the initial polarity of the pulses, three types of PBP were identified. Characteristics of the subsequent PBP trains in the multiple train PBP were also analyzed and they were compared with the first PBP train. Based on the conceptual charge cloud configuration, we found that the inverted dipole is consistent with our observation. We also found that PBP in positive ground flashes during summer thunderstorms in Sweden are weak since the average ratios of the PBP peak to the first return stroke peak lie only between 0.21 and 0.26 . Possible reasons for no detection of PBP and the different types of PBP observed were also discussed.
\end{abstract}

Keywords: lightning; positive ground flashes; preliminary breakdown pulses; multiple train PBP

\section{Introduction}

\subsection{Positive Ground Flash}

Positive ground flashes are ground flashes that transport positive charges from cloud to ground. Although they account for only 10\% of total global cloud-to-ground (CG) lightning [1], they tend to produce strokes with higher peak current and larger charge transfers, making them more dangerous than their negative counterpart. Among the characteristics that are thought to be associated with positive ground flashes is the significant, in-cloud discharge activity that precedes the return stroke (RS) lasting on average, in excess of $100 \mathrm{~ms}$ and $200 \mathrm{~ms}$ [1]. According to [2], this initial breakdown, often referred to as preliminary breakdown, is the in-cloud (IC) process that initiates or leads to the initiation of the downward-moving stepped leaders. The downward-moving leaders will then propagate towards the ground, inducing upward-connecting leaders in the process that will attempt 
to connect to the downward-moving leaders. A complete conducting path will be formed when they meet and a wave of ground potential will travel along the path towards the cloud in a process called the return stroke [3].

\subsection{Review on Previous Studies}

As a process that initiates lightning flashes, various studies have been conducted to characterize preliminary breakdown (PB) in both ground and cloud flashes. Observations have been made by using electromagnetic field measurements for positive ground flashes (e.g., [4-10]), negative ground flashes (e.g., [11-17]) and cloud flashes (e.g., [18-21]). Recently, many new findings have been made by observations with high-speed video camera (e.g., [22-24]) and three-dimensional (3D) location network (e.g., [25-27]). Stolzenburg et al. [22], for example, observed burst of luminosity during the initial breakdown stage of negative ground flashes and IC flashes. They found that the increase in luminosity in the high-speed video data is coincident with the PB pulses in the fast electric field change records. Further study by Stolzenburg et al. [23] later showed that the burst of luminosity is directly related to the PB pulse amplitude. In another study, Campos and Saba [24] observed one stepped leader for a negative ground flash. Their results suggested that the beginning of the initial breakdown pulse trains occurred simultaneously with an early, fast, and bright leader or streamer propagation. The observed pulses were found to change from bipolar to unipolar structure, and the transition coincided with channel luminosity reduction and propagation speed. Recently, Wu et al. [27] who studied the PB process in IC flashes found that PB in most IC flashes has an initiation altitude that ranges from $5-10 \mathrm{~km}$ and IC flashes initiated at higher altitude have lower vertical speed. They also demonstrated that characteristics of the PB pulse trains have close connections with the initiation altitude and upward propagation speed.

Compared to negative ground flashes, however, information about PB in positive CG lightning, is still scarce, as pointed out by Marshal et al. in [17]. Based on the information found in the literature, characteristics of the preliminary breakdown pulses (PBP) in positive ground flashes can be summarized as follows.

\subsubsection{Overall Pulse Shape and Polarity of the Initial Half Cycle}

Individual preliminary breakdown pulses are typically bipolar as reported by many investigators [4-9]. The initial polarity of the pulses can either be the same or opposite to that of the first return stroke [4-10]. In contrast, polarity of the PBP in negative ground flashes was found to be similar to the polarity of the first return stroke $[8,9,13,28]$. Recently, Baharudin et al. [15] observed that some PBP in negative ground flashes can also have opposite initial polarity to that of the following negative return strokes though the authors said it remains an open question.

Based on the pulses initial polarity, the PBP have been classified into either same or opposite polarity PBP [4,7,8,10]. Several researchers have also identified PBP with composite initial polarity [5,6,9] and PBP with two distinct regions [5]. Numerous reasons and hypotheses have been suggested for the occurrence. According to Qie et al. [9], since positive ground flashes seemed to occur when the thunderstorm started to dissipate and the main negative charge centre was weakened, negative charge centre under the main positive charge centre may trigger same polarity PBP and eventually form a positive ground flash. Also, they discussed that different polarity PBP trains might take place between the main negative and lower positive charge centres (as [29] assumed), similar to the preliminary breakdown processes in negative ground flashes, but the negative charge is largely expended in the positive ground flashes cases and repolarized in the main positive charge centre, initiating a positive leader to ground. As for the irregular type PBP, Qie et al. [9] stated that the PBP trains might contain breakdown discharges between both the upper and lower two charge layers. Gomes and Cooray [5], who identified four types of bipolar pulse trains gave two possible reasons for the different types. One being the geometrical alignment of the channel, while the second possibility 
is the breakdown between several combinations of regions in the cloud that may give rise to the ground flash.

\subsubsection{PBP Peak Amplitude Relative to Return Stroke Peak}

Several researchers have analyzed the strength of the PBP by comparing the PBP peak amplitude relative to the first return stroke peak. Wu et al. [8] found that positive ground flashes are unlikely to be associated with very strong PBP and they are much weaker than those in negative ground flashes. According to Wu et al. [8], their conclusion was in agreement with the observation by Brook et al. [12] who noted that in winter thunderstorm, negative ground flashes could have very intense PBP that was sometimes even stronger than the return stroke, but positive ground flashes had very weak PBP both in winter and summer. Qie et al. [9], however, concluded that based on their results, the preliminary breakdown process radiates strongly in positive ground flashes.

\subsubsection{Temporal Characteristics}

Temporal characteristics of the PBP such as the interpulse duration, overall pulse duration, and pulse train duration have also been studied. Ushio et al. [4] found that the values for both the interpulse duration and overall pulse duration were half of those of negative ground flashes reported by [18] while the value of the overall pulse duration was consistent with the value of the pulses associated with cloud flashes reported by [30]. Gomes and Cooray [5], on the other hand, found that the PBP pulse characteristics were somewhat similar to the breakdown pulses preceding negative ground flashes, though confined to a much wider range. Wu et al. [8] too found that some characteristics such as the zero crossing time and pulse train duration were similar to that of negative ground flashes but some characteristics such as the interpulse duration were different.

\subsection{Significance of Study}

As stated by Wu et al. [8], it is still not clear exactly what happens during preliminary breakdown process and according to [31], it has not been established yet whether positive ground flashes draw on the upper positive charge or the lower positive charge, or still another positive charge reservoir. Many suggestions have been put forward but according to Qie et al. [9], the consensus about the initiating mechanisms of positive ground flashes has not been reached. The study of the preliminary breakdown process before positive return strokes is therefore important as it helps to resolve the understanding of the in-cloud process that initiates positive ground flashes. Secondly, Marshal et al. [17] found that the study of PBP in positive ground flashes is relatively limited compared to PBP in negative ground flashes. They came to this conclusion when analyzing the percentage of lightning flashes that begin with initial breakdown pulses. They found that only a few have investigated PBP before positive ground flashes (e.g., $[4,5]$ ) and these studies did not include the statistics on how many positive ground flashes begin with initial breakdown pulses. This caused them to restrict their analysis to negative ground flashes only. The findings from this study would then add to the existing statistics of the PBP characteristics in positive ground flashes and help to improve our overall understanding of positive ground flashes.

\subsection{Objective}

This paper presents the characteristics of the PBP observed in positive ground flashes during 2014 summer thunderstorms in Uppsala, Sweden $\left(59.837^{\circ} \mathrm{N}, 17.646^{\circ} \mathrm{E}\right)$. Electric field changes preceding positive return strokes from remote electric field measurement were analyzed. We obtained the percentage of the positive ground flashes with detectable PBP and the detection percentage according to the distance of the first return stroke, and classified the PBP based on the number of trains observed preceding the first return stroke. Their characteristics such as the PBP polarity, PBP peak amplitude relative to the first return stroke peak and their temporal characteristics were also determined. Comparison studies were then made with findings from previous studies. 


\subsection{Sign Convention}

The atmospheric electricity sign convention is used throughout the paper according to which a downward directed electric field is considered to be positive.

\section{Experiments}

The overall cloud-to-ground lightning flash is known to be composed of a number of processes such as preliminary breakdown, stepped leaders, connecting leaders, return stroke, recoil leaders, $\mathrm{K}$-changes, continuing currents, M-components, dart leaders, and subsequent return strokes [3]. Since these processes are associated with the motion of charge, they can be studied via measurement of the electromagnetic fields associated with that charge motion [2].

\subsection{Measurement Setup}

Measurements of the electric fields generated by the ground flashes were carried out in Uppsala, Sweden $\left(59.837^{\circ} \mathrm{N}, 17.646^{\circ} \mathrm{E}\right)$ from June to August 2014 during the summer season. They were conducted at a station close to the Division of Electricity, Uppsala University.

The measurement setup consisted of broadband antenna systems (comprised of a parallel plate antenna and a vertical whip antenna), a DL850 Yokogawa transient recorder and a Meinberg M400 GPS antenna system. Signals from both antennas were fed into the transient recorder by using RG58 coaxial cables with proper termination to avoid unnecessary reflections.

The parallel plate antenna was used to detect the fast variation (i.e., fast field) of the electric field generated by the ground flash while the vertical whip antenna was used to detect the slow variation (i.e., slow field). Each antenna has a buffer amplifier circuit with decay time constant of $15 \mathrm{~ms}$ for fast field and $1 \mathrm{~s}$ for slow field. Detailed description on the antenna system and the buffer electronic circuits can be found in [32]. Further readings can also be found in $[15,16]$ since the antenna systems used were identical.

The transient recorder is a high-speed, high-resolution recorder with a 12-bit resolution and sampling rate of $100 \mathrm{M}$ sample/sec at $10 \mathrm{~ns}$ interval. The transient recorder was triggered based on the voltage amplitude of the incoming signal from the parallel plate antenna. The trigger level was set above noise level at $50 \mathrm{mV}$ minimum. During the measurement period, the trigger level would be changed depending on how close the thunderstorm was, monitored through the Swedish Meteorological and Hydrological Institute (SMHI) website and observation at site. The closer the thunderstorm to the station, the higher the trigger level would be set in order to ensure close flashes would be recorded. The recording length was set to $1 \mathrm{~s}$ to ensure that the whole activity would be captured. The transient recorder was set to work in a pre-trigger mode of $20 \%$ (i.e., $200 \mathrm{~ms}$ ) so that signals before and after the trigger pulse could be recorded.

The GPS antenna system provided timing information for the event. To obtain the location of these ground flashes, data from the Swedish lightning locating system (LLS) were used. The LLS data were also used to double-check the stroke polarity of the recorded waveforms. The Swedish LLS consists of 10 sensors [33] with an overall detection efficiency of about $85 \%$ [34].

\subsection{Sample Size}

A total of 3025 lightning data were recorded during the measurement period. From this, 299 positive ground flashes were identified. After undergoing a careful selection process, a total of 51 positive ground flashes located 6-130 km from the measuring station were selected for the final analysis. Many signals were removed because they were too small to be analyzed while some were removed due to signal saturation. A few were discarded because the electric field waveforms were not fully captured by the transient recorder. Pulse activity at the end of the $1 \mathrm{~s}$ recording length could still be seen which might have indicated that the process was still continuing. 


\subsection{Criteria for PBP Identification}

The signatures of the electromagnetic fields depend on the physical processes of the lightning flash, and hence, they can be used to identify the different processes associated with the ground flash. The positive return stroke, for example, is indicated by an abrupt and considerable electric field change pulse in the fast field record with coincident field change in the slow field record [35]. For preliminary breakdown, the electrostatic field generated by the process starts to increase slowly for several tens to several hundreds of milliseconds and ends with a burst of pulses having a duration of the order of a millisecond [3]. This electrostatic field change can be seen from the slow field record while the pulse burst, which is mainly radiation, can be seen from the fast field record.

From the measured fast field records, the PBP can be identified as the initial pulse train that precedes the first return stroke, normally found at the beginning of the measured waveform. Once the pulse train has been identified, we used the same criteria for the selection of individual pulses as described in [14]. Only pulses with peak-to-peak amplitudes equal to or exceeding twice that of the average noise level were considered since this condition would result in readable pulses for the analysis. In addition, the pulses were considered as not belonging to the pulse train if they were separated from the last pulse of the train by at least $2 \mathrm{~ms}$. As for the noise level, it was obtained by calculating the average value of the noise peaks at the quiet stage with little associated lightning pulse [6].

\section{Results}

In the study, electric field changes preceding the first return stroke in 51 positive ground flashes were analyzed. The analyses were done based on the radiation field pulses associated with the preliminary breakdown process in positive ground flashes.

\subsection{Positive Ground Flashes with Detectable PBP Trains}

Out of 51 positive ground flashes (+CG) selected, PBP trains were observed in $44(86 \%)$ of the cases while for the remaining $7(14 \%)$, no PBP trains were detected. In previous studies, Schumann et al. [7] found that all flashes (100\%) presented breakdown pulses prior to the return stroke while Qie et al. [9] found $48 \%$ of the positive ground flashes were preceded by PBP. In contrast, Nag and Rakov [10] only found that 8 out of 52 positive ground flashes $(15 \%)$ had detectable PBP trains. Wu et al. [8], who analyzed 36 positive ground flashes from winter lightning measurement in Japan found 26 were preceded by PBP $(72 \%)$. The comparisons are given in Table 1 . Comparing the percentage from different locations, the values varied significantly. However, no dependence with latitude were observed.

Table 1. Percentage of positive ground flashes (+CG) with detectable preliminary breakdown pulses (PBP).

\begin{tabular}{|c|c|c|c|c|c|}
\hline \multirow[b]{2}{*}{ Researcher (Year) } & \multirow[b]{2}{*}{ Location } & \multirow[b]{2}{*}{$\begin{array}{c}\text { Type of Thunderstorms } \\
\text { (Breakdown of Sample Size) }\end{array}$} & \multirow[b]{2}{*}{$\begin{array}{l}\text { Sample } \\
\text { Size, N }\end{array}$} & \multicolumn{2}{|c|}{ No of + CG } \\
\hline & & & & $\begin{array}{c}\text { PBP } \\
\text { Detected }\end{array}$ & $\begin{array}{l}\text { PBP not } \\
\text { Detected }\end{array}$ \\
\hline Present study & $\begin{array}{c}\text { Uppsala, Sweden } \\
\left(59.837^{\circ} \mathrm{N}, 17.646^{\circ} \mathrm{E}\right)\end{array}$ & Summer thunderstorm (51) & 51 & $44(86 \%)$ & $7(14 \%)$ \\
\hline Qie et al. (2013) & $\begin{array}{l}\text { Da Hinggan Ling, China } \\
\left(50.4^{\circ} \mathrm{N}, 124.1^{\circ} \mathrm{E}\right)\end{array}$ & Summer thunderstorm (185) & 185 & $89(48 \%)$ & $96(52 \%)$ \\
\hline Wu et al. (2013) & $\begin{array}{l}\text { Hokuriku, Japan } \\
\left(\sim 37^{\circ} \mathrm{N}, \sim 136^{\circ} \mathrm{E}\right)\end{array}$ & Winter thunderstorm (36) & 36 & $26(72 \%)$ & $10(28 \%)$ \\
\hline Nag and Rakov (2012) & $\begin{array}{c}\text { Florida, US } \\
\left(\sim 29^{\circ} \mathrm{N}, \sim 82^{\circ} \mathrm{W}\right)\end{array}$ & $\begin{array}{l}\text { Summer thunderstorm (39) } \\
\text { Winter thunderstorm (13) }\end{array}$ & 52 & $8(15 \%)$ & $44(85 \%)$ \\
\hline Schumann et al. (2013) & $\begin{array}{c}\text { Sao Paulo, Brazil } \\
\left(23.212^{\circ} \mathrm{S}, 45.867^{\circ} \mathrm{W}\right)\end{array}$ & Summer thunderstorm (80) & 80 & $80(100 \%)$ & - \\
\hline
\end{tabular}

Note: Data listed in descending latitude. 
Figure 1 shows the percentage of PBP observed according to distance, D of the positive ground flashes from the measuring station. The majority of the PBP were detected when D were less than $25 \mathrm{~km}$ with 16 cases (38\%). This is followed by the $50 \leqslant \mathrm{D}<100 \mathrm{~km}$ range with 11 cases $(26 \%)$ and the $25 \leqslant \mathrm{D}<50 \mathrm{~km}$ range with 10 cases $(24 \%)$. For distances $100 \mathrm{~km}$ and above (assumed pure radiation), there were five cases $(12 \%)$ of PBP observed. In the sample data, there were two positive ground flashes where the distance were not available. The highest number of PBP was detected when the positive ground flashes were closest, while the lowest number of PBP detected was when the positive ground flashes were furthest. However, for distances in the $25-50 \mathrm{~km}$ and $50-100 \mathrm{~km}$ range, we did not see much difference since the number of PBP detected was almost equal.

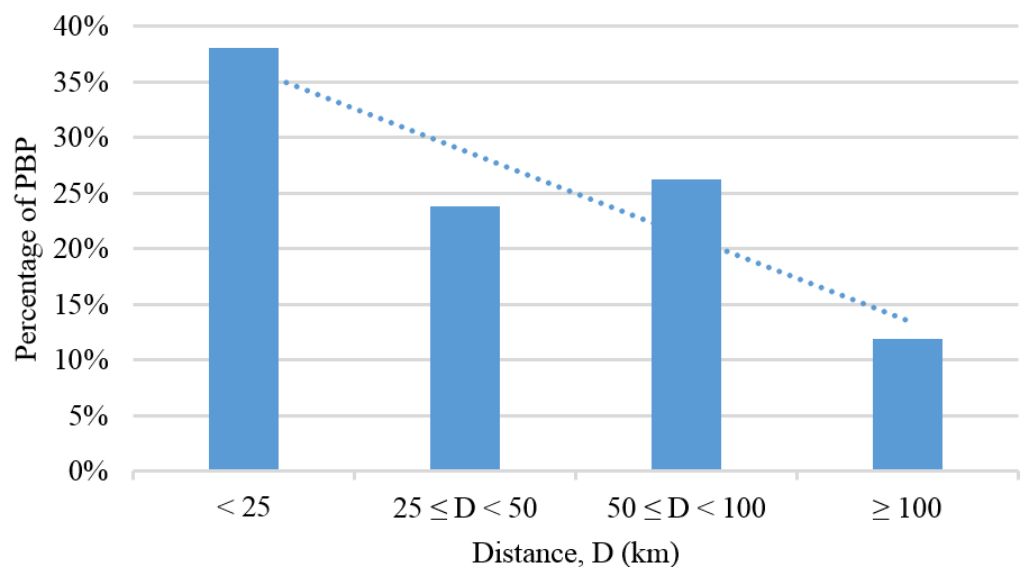

Figure 1. PBP detected according to distance, D (Sample size, $N=42$ ).

\subsection{Classification of $P B P$}

According to [36], preliminary breakdown is technically a cloud discharge since it takes place inside the cloud. It signals the initiation of a downward leader and the pulse burst it produces (having a duration of the order of a millisecond) is the characteristic feature of the process. Since it is the first breakdown event that is associated with the ground flash, it is referred to as preliminary breakdown while other in-cloud discharges are called IC.

In our analysis, there were cases where several pulse bursts, having a duration of the order of a millisecond, were observed preceding the first return stroke while in others, only a single pulse burst could be seen. Based on this, the PBP can be categorized into single train PBP with 37 cases (84\%) and multiple trains PBP with seven cases (16\%). Table 2 gives the overview of the PBP classification while Figure 2 shows sample waveforms for each PBP classification. We analyzed both the characteristics of the first and subsequent PBP trains but the results of the subsequent PBP trains are presented separately in Section 3.6.

Table 2. Classification of PBP based on the number of trains preceding the first RS.

\begin{tabular}{|c|c|c|c|c|c|}
\hline Category & $\%$ & Observation & $\begin{array}{l}\text { IC Activity } \\
\text { Duration }\end{array}$ & Observation & No of + CG \\
\hline \multirow{4}{*}{$\begin{array}{c}\text { Single } \\
\text { train PBP } \\
(N=37)\end{array}$} & \multirow{4}{*}{$84 \%$} & \multirow{2}{*}{ PBP followed by IC } & \multirow{2}{*}{$10-60 \mathrm{~ms}$} & PBP followed by IC, then leader and RS & 5 \\
\hline & & & & PBP followed by IC, then RS & 15 \\
\hline & & \multirow{2}{*}{ PBP not followed by IC } & \multirow{2}{*}{-} & PBP followed by leader then RS & 5 \\
\hline & & & & PBP followed by RS & 12 \\
\hline \multirow{3}{*}{$\begin{array}{l}\text { Multiple } \\
\text { trains PBP } \\
\quad(N=7)\end{array}$} & \multirow{3}{*}{$16 \%$} & PBP followed by IC & $10-120 \mathrm{~ms}$ & PBP followed by IC then RS & 5 \\
\hline & & \multirow{2}{*}{ PBP not followed by IC } & \multirow[t]{2}{*}{-} & PBP followed by leader then RS & 1 \\
\hline & & & & PBP followed by RS & 1 \\
\hline
\end{tabular}

Note: Sample size, $N=44$. 

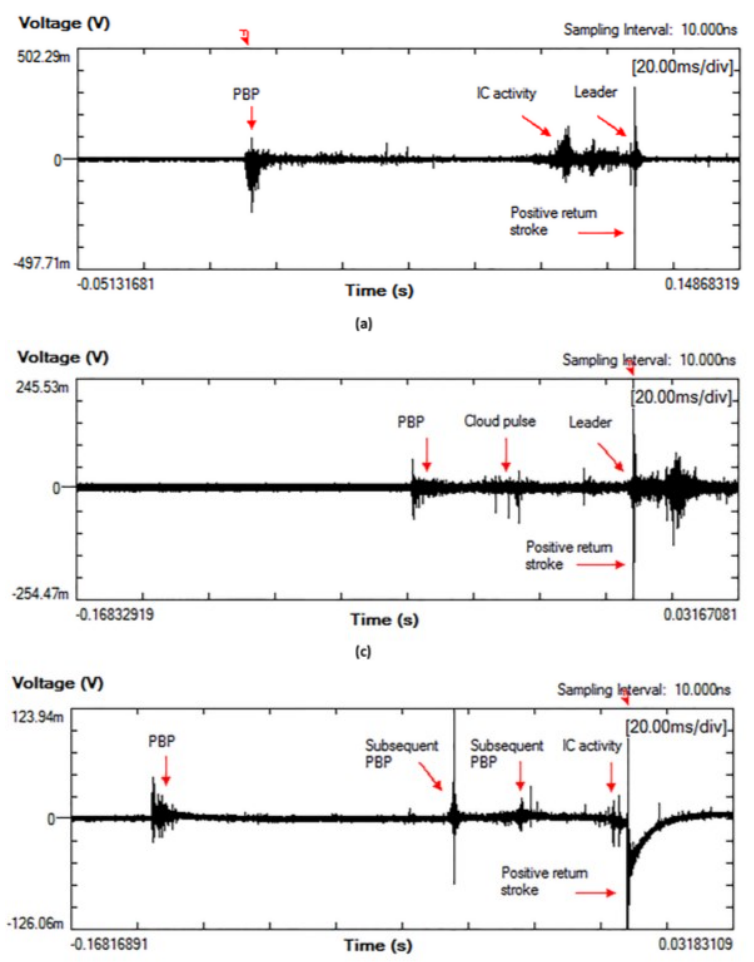

(e)

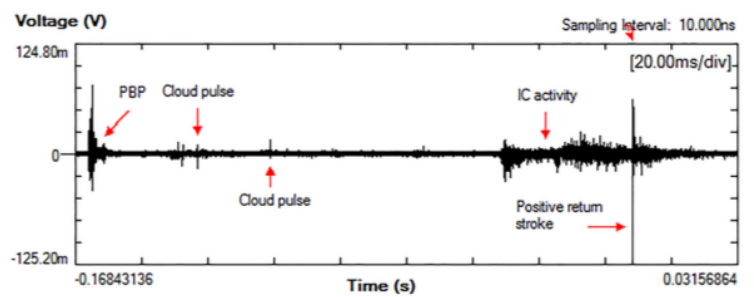

(b)

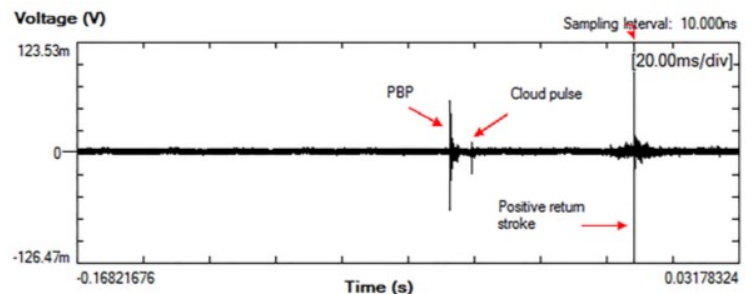

(d)

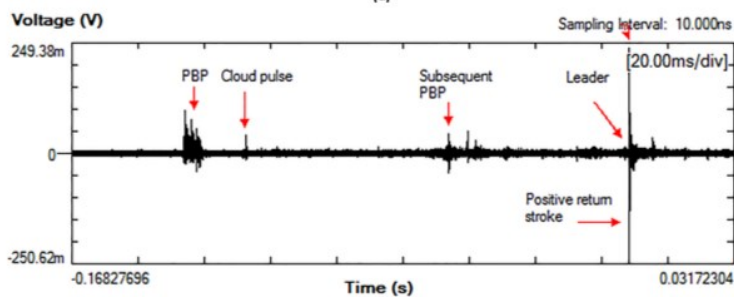

(f)

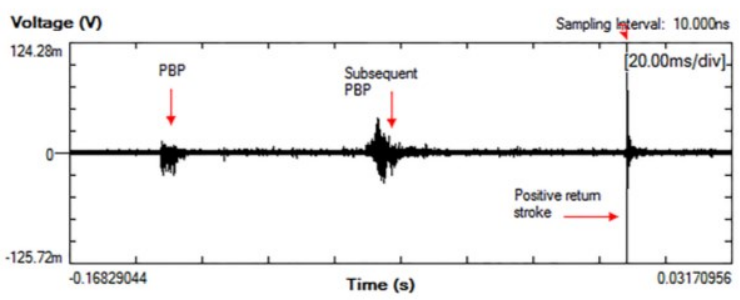

(g)

Figure 2. Sample waveforms showing PBP classifications (a) Single train PBP followed by in-cloud (IC) activity, then leader and return-stroke (RS); (b) Single train PBP followed by IC activity then RS; (c) Single train PBP followed by leader then RS; (d) Single train PBP followed by RS; (e) Multiple trains PBP followed by IC activity then RS; (f) Multiple trains PBP followed by leader then RS; (g) Multiple trains PBP followed by RS.

For single train PBP category, only one PBP train was observed preceding the first return stroke. Most of these PBP trains were followed by IC discharge activity having a duration of 10-60 ms (20 cases), while others (17 cases) did not have any detectable IC activity. For the PBP train followed by IC activity, some trains were followed by pronounced leader pulses and then return stroke (5 cases), while in others ( 15 cases), they were followed by just the return stroke without any detectable leader changes. For PBP train with no detectable IC activity, five of them were followed by pronounced leader pulses and then return stroke, while the remaining 12 were followed by just the return stroke without any detectable leader pulses.

For the case of multiple trains PBP, we observed up to three PBP trains preceding the first return stroke. Since there were no other ground flashes present in the $1 \mathrm{~s}$ record, we assumed that the multiple trains PBP belong to the same positive ground flash. For this category, five cases of the multiple trains PBP were followed by IC having a duration of $10-120 \mathrm{~ms}$ and then followed by a return stroke, while in one case, the PBP trains were followed by pronounced leader pulses and then a return stroke and in another case, the PBP trains were followed by just the return stroke. 


\subsection{Overall Pulse Shape and Polarity of the Initial Half Cycle}

Typically, pulses in the PBP train are bipolar. The majority of the pulses have a smooth initial rising portion. Some pulses have several small pulses superimposed on the rising part while a few others have multiple peaks. Based on the pulses initial half cycle polarity, three types of PBP train have been identified. Out of 44 positive ground flashes that have detectable PBP trains, 21 (48\%) have the same polarity as the first return stroke (Type 1), $15(34 \%)$ have the opposite polarity (Type 2 ) while the remaining eight $(18 \%)$ have composite polarity (Type 3). For Type 3, there are two distinct regions. The first region has either the same or opposite polarity to the return stroke but the second region can be mixed or different from the first region. Figures 3-5 show sample waveforms for Type 1, Type 2, and Type 3 respectively.
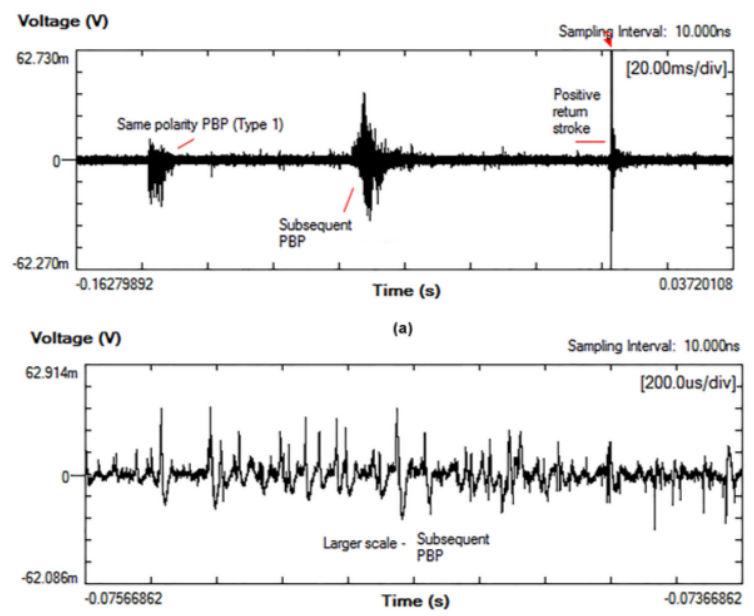

(c)
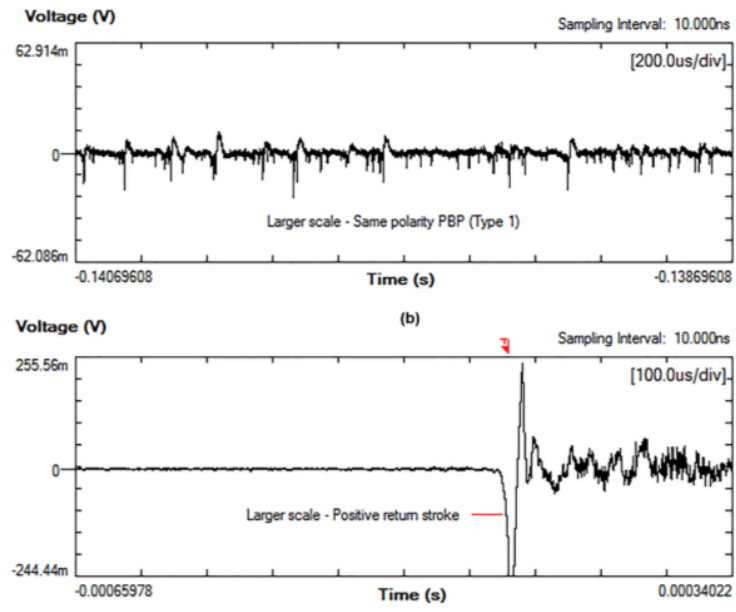

(d)

Figure 3. (a) Type 1 PBP—Same polarity PBP; (b) Zoom in of PBP train having the same polarity pulses as the positive RS; (c) Zoom in of the subsequent PBP trains; (d) Zoom in of positive RS.
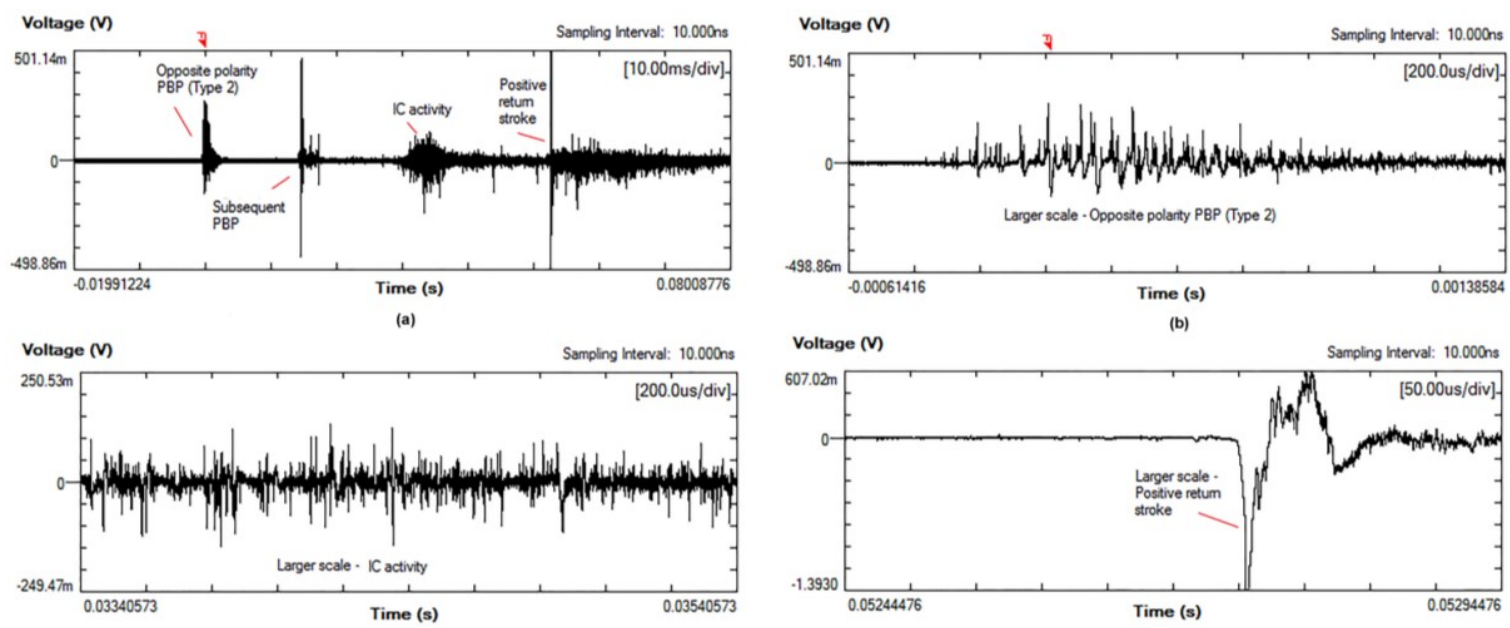

(c)

(d)

Figure 4. (a) Type 2 PBP-Opposite polarity PBP; (b) Zoom in of PBP train having opposite polarity pulses from the positive RS; (c) Zoom in of IC activity; (d) Zoom in of positive RS. 

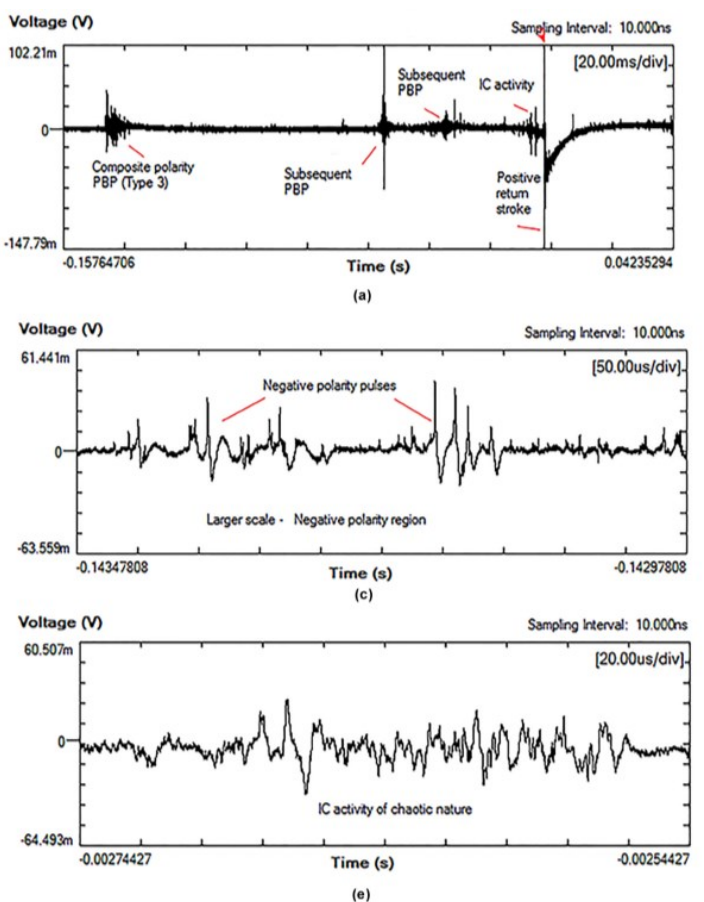
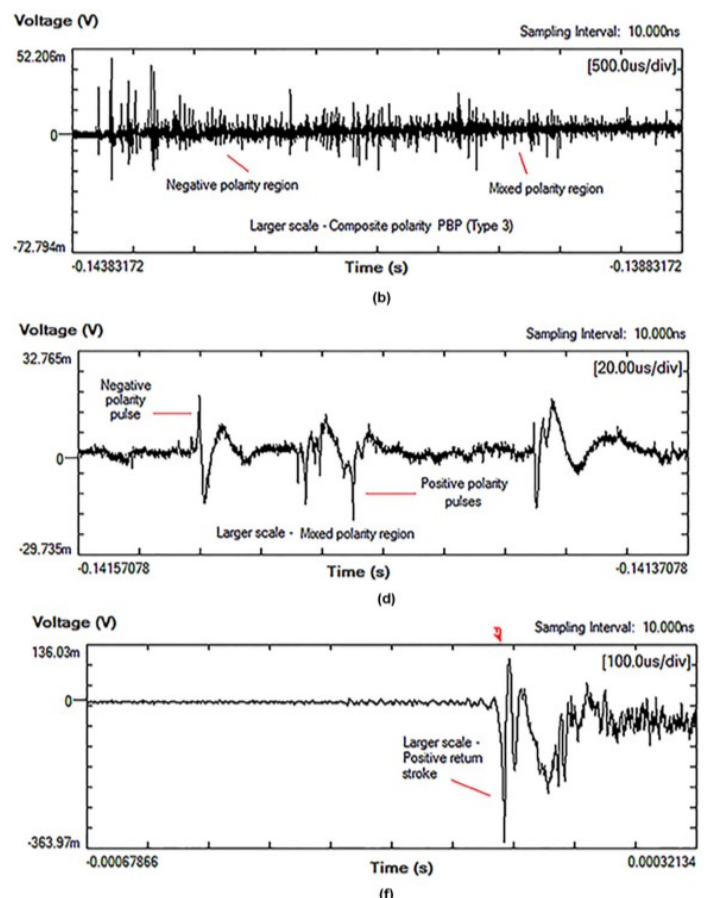

Figure 5. (a) Type 3 PBP-Composite polarity PBP; (b) Zoom in of PBP train having 2 different regions; (c) Zoom in of the first region showing PBP pulses with opposite polarity from the positive RS; (d) Zoom in of the second region showing pulses with mixed polarity; (e) Zoom in of IC activity; (f) Zoom in of positive RS.

Previous studies found that most PBP either have the same or opposite polarity to the first return stroke with the majority having the same polarity as the first return stroke. Ushio et al. [4], for example, found 17 out of 19 cases $(89.5 \%)$ have the same polarity. Nag and Rakov [10] found that seven out of eight cases ( $87.5 \%)$ have the same polarity. Schumann et al. [7] found that $95 \%$ of the 80 samples have the same polarity as the first return stroke. Wu et al. [8], however, found only $11(42 \%)$ had the same polarity while the other 15 had opposite polarity.

Some studies also showed that the PBP can exhibit both polarities. Gomes and Cooray [5], in particular, identified four types of PBP based on the initial polarity. They found that 57 out of 71 cases $(80 \%)$ had the same polarity, five had opposite polarity $(7 \%)$, six exhibited both polarity $(9 \%)$ while the other three had irregular polarity (4\%). Recently, Zhang et al. [6] also identified several types of PBP. They found that in one location, 55\% of the PBP had the same polarity as the first return stroke, $39 \%$ had the opposite polarity and $6 \%$ had composite polarity while in another location, they found $81 \%$ of the PBP had the same polarity, $15 \%$ had the opposite polarity and $4 \%$ had composite polarity. Qie et al. [9] also classified the PBP into three types, namely type S (same), type D (different), and type $\mathrm{C}$ (chaotic) according to the differences in the initial polarity of bipolar pulses from the first return stroke, which account for $62.92 \%, 23.60 \%$, and $13.48 \%$, respectively. The statistics and comparison are shown in Table 3.

Table 3. Percentage of PBP according to initial half cycle polarity.

\begin{tabular}{|c|c|c|c|c|c|c|}
\hline Researcher (Year) & Location & Sample Size, N & Type * & Polarity & No of PBP & $\%$ \\
\hline \multirow{3}{*}{ Present study } & \multirow{3}{*}{$\begin{array}{c}\text { Uppsala, Sweden } \\
\left(59.837^{\circ} \mathrm{N}, 17.646^{\circ} \mathrm{E}\right)\end{array}$} & \multirow{3}{*}{44} & 1 & Same & 21 & $48 \%$ \\
\hline & & & 2 & Opposite & 15 & $34 \%$ \\
\hline & & & 3 & Composite & 8 & $18 \%$ \\
\hline \multirow[b]{2}{*}{ Ushio et al. (1998) } & \multirow{2}{*}{$\begin{array}{l}\text { Hokuriku, Japan } \\
\left(\sim 37^{\circ} \mathrm{N}, \sim 136^{\circ} \mathrm{E}\right)\end{array}$} & \multirow[b]{2}{*}{19} & - & Same & 17 & $89.5 \%$ \\
\hline & & & - & Opposite & 2 & $10.5 \%$ \\
\hline
\end{tabular}


Table 3. Cont.

\begin{tabular}{|c|c|c|c|c|c|c|}
\hline Researcher (Year) & Location & Sample Size, N & Type * & Polarity & No of PBP & $\%$ \\
\hline \multirow{2}{*}{ Nag and Rakov (2012) } & \multirow{2}{*}{$\begin{array}{c}\text { Florida, US } \\
\left(\sim 29^{\circ} \mathrm{N}, \sim 82^{\circ} \mathrm{W}\right)\end{array}$} & \multirow{2}{*}{52} & - & Same & 7 & $87.5 \%$ \\
\hline & & & - & Opposite & 1 & $12.5 \%$ \\
\hline \multirow{2}{*}{ Schumann et al. (2013) } & \multirow{2}{*}{$\begin{array}{c}\text { Sao Paulo, Brazil } \\
\left(23.212^{\circ} \mathrm{S}, 45.867^{\circ} \mathrm{W}\right)\end{array}$} & \multirow{2}{*}{80} & - & Same & 76 & $95 \%$ \\
\hline & & & - & Opposite & 4 & $5 \%$ \\
\hline \multirow{2}{*}{ Wu et al. (2013) } & \multirow{2}{*}{$\begin{array}{l}\text { Hokuriku, Japan } \\
\left(\sim 37^{\circ} \mathrm{N}, \sim 136^{\circ} \mathrm{E}\right)\end{array}$} & \multirow{2}{*}{36} & $+\mathrm{PBP}$ & Same & 11 & $42 \%$ \\
\hline & & & $-\mathrm{PBP}$ & Opposite & 15 & $58 \%$ \\
\hline \multirow{4}{*}{ Gomes and Cooray (2004) } & \multirow{4}{*}{$\begin{array}{l}\text { Uppsala, Sweden } \\
\left(59.8^{\circ} \mathrm{N}, 17.6^{\circ} \mathrm{E}\right)\end{array}$} & \multirow{4}{*}{71} & a & Same & 57 & $80 \%$ \\
\hline & & & $\mathrm{b}$ & Composite & 5 & $7 \%$ \\
\hline & & & c & Opposite & 6 & $9 \%$ \\
\hline & & & d & Irregular & 3 & $4 \%$ \\
\hline \multirow{6}{*}{ Zhang et al. (2013) } & \multirow{3}{*}{$\begin{array}{c}\text { Beijing, China } \\
\left(39.94^{\circ} \mathrm{N}, 116.32^{\circ} \mathrm{E}\right)\end{array}$} & \multirow{3}{*}{100} & I & Same & 55 & $55 \%$ \\
\hline & & & II & Opposite & 39 & $39 \%$ \\
\hline & & & III & Composite & 6 & $6 \%$ \\
\hline & \multirow{3}{*}{$\begin{array}{l}\text { Guangzhou, China } \\
\left(23.34^{\circ} \mathrm{N}, 113.36^{\circ} \mathrm{E}\right)\end{array}$} & \multirow{3}{*}{48} & I & Same & 39 & $81 \%$ \\
\hline & & & II & Opposite & 7 & $15 \%$ \\
\hline & & & III & Composite & 2 & $4 \%$ \\
\hline \multirow{3}{*}{ Qie et al. (2013) } & \multirow{3}{*}{$\begin{array}{l}\text { Da Hinggan Ling, China } \\
\left(50.4^{\circ} \mathrm{N}, 124.1^{\circ} \mathrm{E}\right)\end{array}$} & \multirow{3}{*}{185} & $S$ & Same & 56 & $62.9 \%$ \\
\hline & & & $\mathrm{D}$ & Opposite & 21 & $23.6 \%$ \\
\hline & & & $\mathrm{C}$ & Chaotic & 12 & $13.5 \%$ \\
\hline
\end{tabular}

* Type as defined by the authors.

\subsection{PBP Peak Amplitude Relative to Return Stroke Peak}

The ratio between the largest amplitude of PBP and the return stroke peak was also analyzed. In most cases, the PBP peak values were much smaller than the first return stroke peak. On average, the ratio of the PBP peak to the first return stroke peak is 0.26 for Type 1, 0.22 for Type 2, and 0.21 for Type 3. This is in agreement with observation by previous researchers. Ushio et al. [4] found the mean ratio to be 0.27 with values ranging between 0.02 and 1.9. On the other hand, both Zhang et al. [6] and $\mathrm{Wu}$ et al. [8] found the mean values to be less than 0.20 while Qie et al. [9] found the mean ratio to be 0.32 , which was the highest mean ratio value among all studies compared. Based on the average ratio of the PBP peak to the first return stroke peak, the PBP in positive ground flashes during summer thunderstorms in Sweden can be considered as weak since the mean values for all three types are less than half, ranging only between 0.21 and 0.26 .

In one ground flash, the PBP was found to have a ratio higher than one (1.15), indicating that the PBP peak was higher than the peak of the first return stroke. Ushio et al. [4] also found instances where the peak ratio was higher than one (1.9) but Qie et al. [9] did not find any cases involving PBP peak higher than the return stroke peak. For the one case where we observed the ratio to be higher than one, the positive ground flash was quite close, about $23 \mathrm{~km}$ away from the measuring station and had multiple subsequent return strokes. The initial polarity of the PBP was the same as the first return stroke (Type 1).

The statistics and comparison with previous studies are given in Table 4. Comparing the mean values from different locations, the ratio of the PBP peak to the first return stroke peak varied slightly, ranging between 0.153 and 0.32 . However, no dependence of the mean ratio with latitude can be seen. 
Table 4. Comparison on PBP peak amplitude relative to return stroke peak with previous studies.

\begin{tabular}{|c|c|c|c|c|c|c|}
\hline \multirow{2}{*}{ Researcher (Year) } & \multirow{2}{*}{ Location } & \multirow{2}{*}{ Sample Size, N } & \multirow{2}{*}{ Polarity } & \multicolumn{3}{|c|}{ PBP Peak Amplitude Relative to RS Peak } \\
\hline & & & & Max & Min & Arithmetic Mean \\
\hline \multirow{3}{*}{ Present study } & \multirow{3}{*}{$\begin{array}{l}\text { Uppsala, Sweden } \\
\left(59.837^{\circ} \mathrm{N}, 17.646^{\circ} \mathrm{E}\right)\end{array}$} & \multirow{3}{*}{44} & Same & 1.15 & 0.03 & 0.26 \\
\hline & & & Opposite & 0.74 & 0.04 & 0.22 \\
\hline & & & Composite & 0.43 & 0.07 & 0.21 \\
\hline \multirow{3}{*}{ Qie et al. (2013) } & \multirow{3}{*}{$\begin{array}{l}\text { Da Hinggan Ling, China } \\
\left(50.4^{\circ} \mathrm{N}, 124.1^{\circ} \mathrm{E}\right)\end{array}$} & \multirow{3}{*}{185} & Same & 0.99 & 0.03 & 0.32 \\
\hline & & & Opposite & - & - & - \\
\hline & & & Chaotic & - & - & - \\
\hline \multirow{6}{*}{ Zhang et al. (2013) } & \multirow{3}{*}{$\begin{array}{c}\text { Beijing, China } \\
\left(39.94^{\circ} \mathrm{N}, 116.32^{\circ} \mathrm{E}\right)\end{array}$} & \multirow{3}{*}{100} & Same & 0.524 & 0.021 & 0.197 \\
\hline & & & Opposite & 0.45 & 0.035 & 0.186 \\
\hline & & & Composite & - & - & - \\
\hline & \multirow{3}{*}{$\begin{array}{l}\text { Guangzhou, China } \\
\left(23.34^{\circ} \mathrm{N}, 113.36^{\circ} \mathrm{E}\right)\end{array}$} & \multirow{3}{*}{48} & Same & 0.594 & 0.043 & 0.195 \\
\hline & & & Opposite & 0.272 & 0.035 & 0.153 \\
\hline & & & Composite & - & - & - \\
\hline \multirow{2}{*}{ Wu et al. (2013) } & \multirow{2}{*}{$\begin{array}{l}\text { Hokuriku, Japan } \\
\left(\sim 37^{\circ} \mathrm{N}, \sim 136^{\circ} \mathrm{E}\right)\end{array}$} & \multirow{2}{*}{36} & Same & \multirow{2}{*}{0.48} & - & 0.17 \\
\hline & & & Opposite & & - & 0.18 \\
\hline \multirow{2}{*}{ Ushio et al. (1998) } & \multirow{2}{*}{$\begin{array}{l}\text { Hokuriku, Japan } \\
\left(\sim 37^{\circ} \mathrm{N}, \sim 136^{\circ} \mathrm{E}\right)\end{array}$} & \multirow[b]{2}{*}{19} & Same & \multirow[b]{2}{*}{1.9} & \multirow[b]{2}{*}{0.02} & \multirow[b]{2}{*}{0.27} \\
\hline & & & Opposite & & & \\
\hline
\end{tabular}

\subsection{Temporal Characteristics}

In order to analyze the temporal characteristics of the PBP, we determined the time interval between the largest PBP and the first return stroke, pulse train duration, interpulse duration, individual pulse duration, and total pulse duration for each type. The time interval between the largest PBP and the first return stroke (PBP-RS separation) can be defined as the time between the peak of the largest PBP and the peak of the first return stroke [5-10]. Pulse train duration can be defined as the time interval between the peaks of the first and last pulses in the train [5-7]. Interpulse duration is the time interval between the peaks of two consecutive pulses [5-9,14]. For individual pulse duration and total pulse duration, we determined the pulse duration for the first half cycle $\left(\mathrm{T}_{1}\right)$ and the second half cycle $\left(T_{2}\right)$ of an individual bipolar pulse $[5,7,9]$. Thus, $T_{1}+T_{2}$ is approximately equal to the total pulse duration $[5,7,9,14]$. Figure 6 shows a sample waveform illustrating the temporal characteristics of the PBP.

For Type 1, Type 2, and Type 3, the average PBP-RS separations were found to be $75.1 \mathrm{~ms}, 114.6 \mathrm{~ms}$, and $59.2 \mathrm{~ms}$, while the pulse train durations were $5.9 \mathrm{~ms}, 2.6 \mathrm{~ms}$, and $24.8 \mathrm{~ms}$, respectively. Also, the interpulse durations were found to be $115.1 \mu \mathrm{s}, 93.7 \mu \mathrm{s}$, and $57.2 \mu \mathrm{s}$. As for individual pulse duration, the average values for the first half cycle $\left(\mathrm{T}_{1}\right)$ were $8.2 \mu \mathrm{s}, 3.8 \mu \mathrm{s}$, and $4.9 \mu \mathrm{s}$ while for the second half cycle $\left(\mathrm{T}_{2}\right)$ the values were $10.0 \mu \mathrm{s}, 7.3 \mu \mathrm{s}$, and $8.3 \mu \mathrm{s}$. Total pulse durations $\left(\mathrm{T}_{1}+\mathrm{T}_{2}\right)$ were found to be $16.9 \mu \mathrm{s}, 10.0 \mu \mathrm{s}$, and $12.8 \mu \mathrm{s}$. These values were for Type 1, Type 2, and Type 3 respectively.

The results were then compared with previous studies by Zhang et al. [6] and Gomes and Cooray [5] since both studies reported similar types of PBP trains based on the pulses initial half cycle polarity. We also compared our results with $\mathrm{Wu}$ et al. [8] since they separated their results based on the polarity of the PBP. The statistics are given in Table 5. 


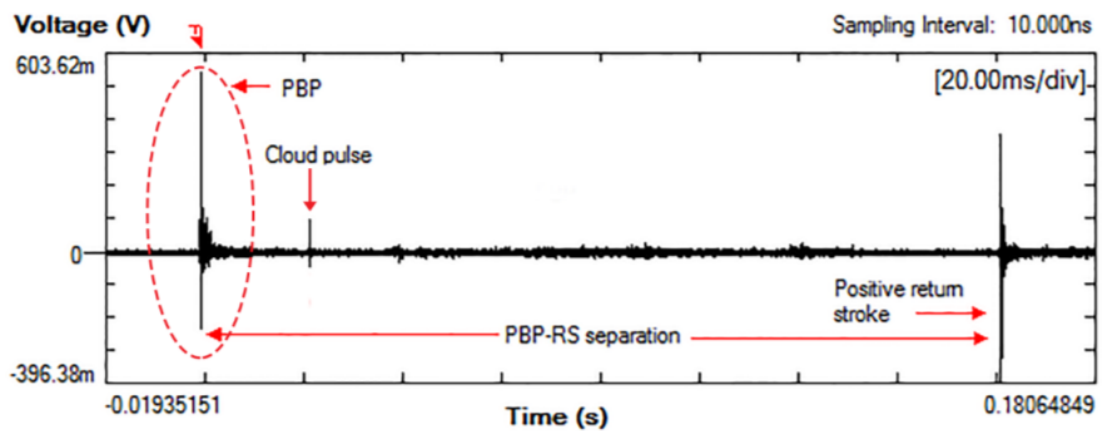

(a)

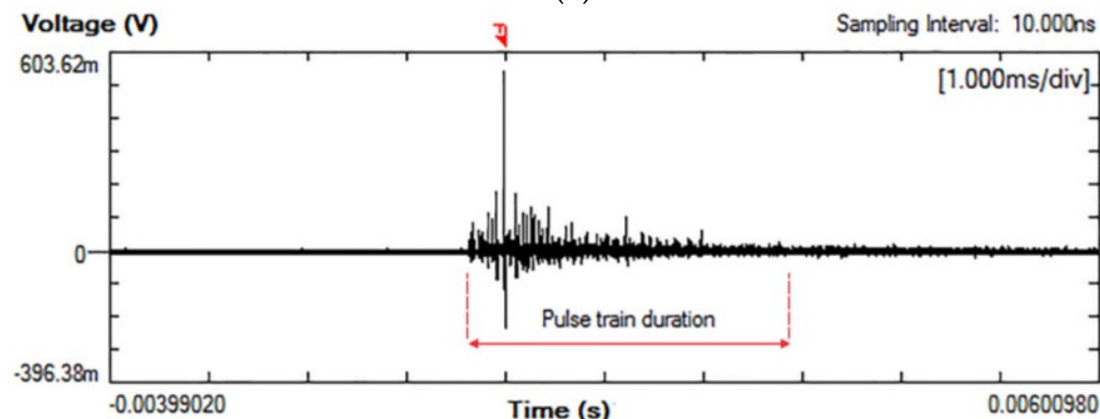

(b)

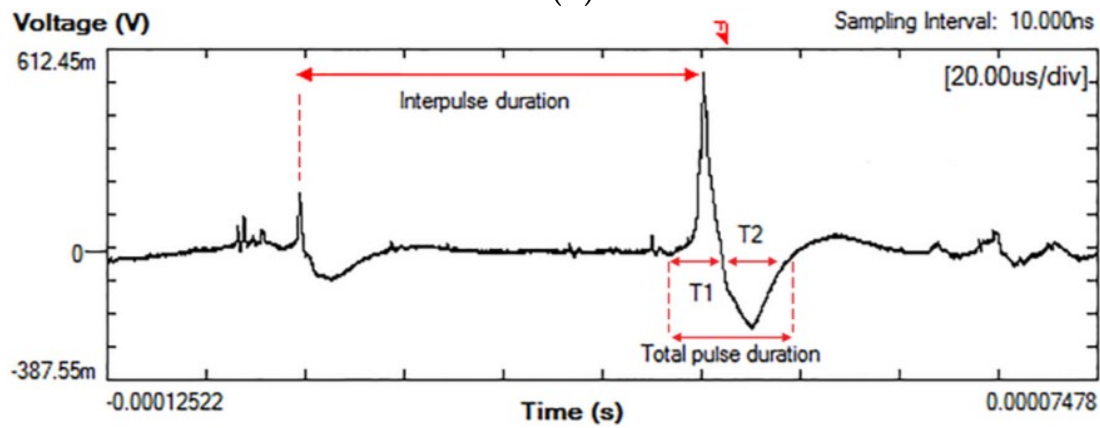

(c)

Figure 6. Temporal characteristics of the PBP (a) Sample waveform showing PBP-RS separation; (b) Zoom in of the waveform showing the pulse train duration; (c) Zoom in of the waveform showing the interpulse duration, pulse duration for the first half cycle $\left(\mathrm{T}_{1}\right)$ and the second half cycle $\left(\mathrm{T}_{2}\right)$ of an individual bipolar pulse, and total pulse duration $\left(\mathrm{T}_{1}+\mathrm{T}_{2}\right)$.

Table 5. Comparison of PBP temporal characteristics with previous studies.

\begin{tabular}{|c|c|c|c|c|c|c|c|c|c|}
\hline \multirow{2}{*}{$\begin{array}{l}\text { Researcher } \\
\text { (Year) }\end{array}$} & \multirow[t]{2}{*}{ Location } & \multirow{2}{*}{$\begin{array}{l}\text { Sample } \\
\text { Size, } \\
\text { N }\end{array}$} & \multirow[t]{2}{*}{ Polarity } & \multirow{2}{*}{$\begin{array}{l}\text { PBP-RS } \\
\text { Separation } \\
\quad(\mathrm{ms})\end{array}$} & \multirow{2}{*}{$\begin{array}{l}\text { Pulse Train } \\
\text { Duration } \\
\text { (ms) }\end{array}$} & \multicolumn{3}{|c|}{$\begin{array}{l}\text { Individual Pulse } \\
\text { Duration }(\mu \mathrm{s})\end{array}$} & \multirow{2}{*}{$\begin{array}{l}\text { Interpulse } \\
\text { Duration } \\
\quad(\mu s)\end{array}$} \\
\hline & & & & & & $\mathrm{T}_{1}$ & $\mathrm{~T}_{2}$ & $\mathrm{~T}_{1}+\mathrm{T}_{2}$ & \\
\hline \multirow{2}{*}{$\begin{array}{l}\text { Present } \\
\text { study }\end{array}$} & \multirow{2}{*}{$\begin{array}{c}\text { Uppsala, } \\
\text { Sweden } \\
\left(59.837^{\circ} \mathrm{N},\right. \\
\left.17.646^{\circ} \mathrm{E}\right)\end{array}$} & \multirow{2}{*}{44} & Opposite & 114.6 & 2.6 & 3.8 & 7.3 & 10.0 & 9.7 \\
\hline & & & Composite & 59.2 & 24.8 & 4.9 & 8.3 & 12.8 & 57.2 \\
\hline \multirow{4}{*}{$\begin{array}{l}\text { Gomes } \\
\text { and } \\
\text { Cooray } \\
(2004)\end{array}$} & \multirow{4}{*}{$\begin{array}{c}\text { Uppsala, } \\
\text { Sweden } \\
\left(59.8^{\circ} \mathrm{N}, 17.6^{\circ} \mathrm{E}\right)\end{array}$} & \multirow[t]{4}{*}{71} & Composite & 81 & 1.3 & 13 & 13 & 27 & 62 \\
\hline & & & Reg. 2 & 77 & 2.8 & 12 & 14 & 26 & 38 \\
\hline & & & Opposite & 44 & 2.1 & 16 & 15 & 31 & 51 \\
\hline & & & Irregular & - & - & - & - & - & - \\
\hline
\end{tabular}


Table 5. Cont.

\begin{tabular}{|c|c|c|c|c|c|c|c|c|c|}
\hline \multirow{2}{*}{$\begin{array}{l}\text { Researcher } \\
\text { (Year) }\end{array}$} & \multirow{2}{*}{ Location } & \multirow{2}{*}{$\begin{array}{l}\text { Sample } \\
\text { Size, } \\
\text { N }\end{array}$} & \multirow[t]{2}{*}{ Polarity } & \multirow{2}{*}{$\begin{array}{l}\text { PBP-RS } \\
\text { Separation } \\
\text { (ms) }\end{array}$} & \multirow{2}{*}{$\begin{array}{l}\text { Pulse Train } \\
\text { Duration } \\
\text { (ms) }\end{array}$} & \multicolumn{3}{|c|}{$\begin{array}{l}\text { Individual Pulse } \\
\text { Duration }(\mu \mathrm{s})\end{array}$} & \multirow{2}{*}{$\begin{array}{l}\text { Interpulse } \\
\text { Duration } \\
\quad(\mu s)\end{array}$} \\
\hline & & & & & & $\mathrm{T}_{1}$ & $T_{2}$ & $\mathrm{~T}_{1}+\mathrm{T}_{2}$ & \\
\hline \multirow{4}{*}{$\begin{array}{l}\text { Zhang } \\
\text { et al. (2013) }\end{array}$} & \multirow{2}{*}{$\begin{array}{c}\text { Beijing, China } \\
\left(39.94^{\circ} \mathrm{N}\right. \\
\left.116.32^{\circ} \mathrm{E}\right)\end{array}$} & \multirow{2}{*}{100} & Opposite & 112.7 & 2.3 & - & - & 23 & 100 \\
\hline & & & Composite & - & - & - & - & - & - \\
\hline & \multirow{2}{*}{$\begin{array}{c}\text { Guangzhou, } \\
\text { China }\left(23.34^{\circ} \mathrm{N},\right. \\
\left.113.36^{\circ} \mathrm{E}\right)\end{array}$} & \multirow[t]{2}{*}{48} & Opposite & 112.1 & 2.3 & - & - & 26 & 195 \\
\hline & & & Composite & - & - & - & - & - & - \\
\hline \multirow{2}{*}{$\begin{array}{l}\text { Wu et al. } \\
\text { (2013) }\end{array}$} & \multirow{2}{*}{ 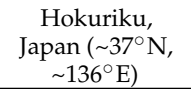 } & \multirow{2}{*}{36} & Same & 17 & 0.8 & - & - & - & 44 \\
\hline & & & Opposite & 1.1 & & - & - & - & 47 \\
\hline
\end{tabular}

In general, our values were comparable to that of Zhang et al. [6] who studied PBP trains at two different locations in China. Their values for both PBP-RS separation and pulse train duration for PBP having opposite polarity to the return stroke were similar to those which we obtained. Our PBP-RS separations for PBP with the same polarity were slightly lower while our pulse train durations were slightly higher. Our interpulse duration and total pulse duration were lower for both Type 1 and 2 . Results from Gomes and Cooray [5], on the other hand, were slightly different despite being from the same location. Our PBP-RS separation, pulse train duration, and interpulse duration were higher while individual pulse duration and total pulse duration were lower, for all PBP types. One possible reason for the difference could be because we had a smaller sample size and this could affect the results to a certain extent. As for the findings from Wu et al. [8], their pulse train duration and interpulse duration were smaller than the rest of the results compared here.

\subsection{Characteristics of Subsequent PBP Trains}

Out of seven positive ground flashes observed to have multiple trains PBP, six flashes had one subsequent PBP train while one flash had two subsequent PBP trains following the first PBP train. Similar to the first PBP trains, the pulse structure for the subsequent PBP trains is typically bipolar. Some pulses have smooth initial rising portion while others have several small pulses superimposed on the rising part. A few pulses have multiple peaks. Based on the pulses initial half cycle, polarity of two PBP trains were found to be opposite to that of the first return stroke. Five PBP trains had composite polarity in a single region while the remaining one had composite polarity with two distinct regions.

Characteristics of the eight subsequent PBP trains are given in Table 6. Compared to the first PBP train, the parameter values obtained for the subsequent PBP trains were relatively smaller. The PBP peak amplitude relative to the return stroke peak, for example, was found to be 0.14 on average while the value for the first PBP train was 0.24 . The pulse train duration, individual pulse duration, and interpulse duration for the subsequent PBP trains were found to be $3.63 \mathrm{~ms}, 11.05 \mu \mathrm{s}$, and $43.78 \mu \mathrm{s}$ respectively compared to $7.41 \mathrm{~ms}, 13.80 \mu \mathrm{s}$, and $95.48 \mu \mathrm{s}$ of the first PBP train. Additionally, the time interval between the largest PBP and the first return stroke (PBP-RS separation) was found to be $73.23 \mathrm{~ms}$.

Table 6. Comparison on PBP characteristics between first and subsequent PBP trains.

\begin{tabular}{|c|c|c|c|c|c|c|c|c|c|c|c|}
\hline \multirow[t]{2}{*}{$\begin{array}{l}\text { Researcher } \\
\text { (Year) }\end{array}$} & \multirow[t]{2}{*}{$\begin{array}{c}\text { PBP } \\
\text { Category }\end{array}$} & \multirow[t]{2}{*}{$\begin{array}{l}\text { Sample } \\
\text { Size, N }\end{array}$} & \multicolumn{3}{|c|}{$\begin{array}{l}\text { PBP Peak Amplitude } \\
\text { Relative to RS Peak }\end{array}$} & \multirow{2}{*}{$\begin{array}{l}\text { PBP-RS } \\
\text { Separation } \\
\text { (ms) }\end{array}$} & \multirow{2}{*}{$\begin{array}{c}\text { Pulse } \\
\text { Train } \\
\text { Duration } \\
(\mathrm{ms})\end{array}$} & \multicolumn{3}{|c|}{$\begin{array}{l}\text { Individual Pulse } \\
\text { Duration }(\mu \mathrm{s})\end{array}$} & \multirow{2}{*}{$\begin{array}{l}\text { Interpulse } \\
\text { Duration } \\
\quad(\mu \mathrm{s})\end{array}$} \\
\hline & & & Max & Min & $\begin{array}{l}\text { Arithmetic } \\
\text { Mean }\end{array}$ & & & $\mathbf{T}_{1}$ & $\mathbf{T}_{2}$ & $\mathrm{~T}_{1}+\mathrm{T}_{2}$ & \\
\hline \multirow[t]{2}{*}{$\begin{array}{c}\text { Present } \\
\text { study }\end{array}$} & $\begin{array}{l}\text { First PBP } \\
\text { train }\end{array}$ & 44 & 1.15 & 0.03 & 0.24 & 85.66 & 7.41 & 6.08 & 8.80 & 13.80 & 95.48 \\
\hline & $\begin{array}{l}\text { Subsequent } \\
\text { PBP trains }\end{array}$ & 8 & 0.38 & 0.04 & 0.14 & 73.23 & 3.63 & 5.02 & 7.68 & 11.05 & 43.78 \\
\hline
\end{tabular}




\section{Discussion}

\subsection{Reasons for No Detection of PBP}

There could be several reasons why some PBP were not detected in positive ground flashes. One is that the PBP amplitude might be relatively small, below noise level of the measurement site, making it too small to be detected. In a recent study for negative ground flashes, Marshal et al. [17] said that the detection of PBP before negative ground flashes regardless of amplitude requires the sensor to be close enough to the parent CG flash to reveal pulses above the local noise level and the sensor's noise level. Even though their study was restricted only for negative ground flashes (due to lack of statistics on positive ground flashes), our observation seems to agree with their suggestion since we found that most of the PBP were detected when the positive ground flashes were close (less than $25 \mathrm{~km}$ ). Also, all our seven positive ground flashes without PBP detected were quite far at distances ranging from $64-126 \mathrm{~km}$.

The pre-trigger setting could also play a role. Electric field measurements by Rust et al. [37] showed that the intracloud discharge activity can last on average $241 \mathrm{~ms}$ (between 40-800 ms) while Fuquay [35] indicated that it can last on average $130 \mathrm{~ms}$ (between 65-210 ms). Based on this, it is possible that some of the PBP might not have been detected because they occurred outside the pre-trigger setting (i.e., $200 \mathrm{~ms}$ ) of our transient recorder.

\subsection{Different Polarity of PBP in Positive Ground Flashes}

The basic charge structure of a normal thundercloud is a vertical tripole consisting of three regions: the main positive charge centre at the top, the main negative charge centre in the middle and a smaller positive charge pocket at the lower level [31]. For thunderstorms with normal tripolar structure, the same polarity PBP (Type 1) can be viewed as the interaction between the main positive and main negative charge centres while the opposite polarity PBP (Type 2) can be viewed as the interaction between the main negative charge centre and the lower positive cloud region.

For such a case, the PBP-RS separation for same polarity PBP (Type 1) should probably be higher than the opposite polarity PBP (Type 2) since the main positive charge centre is located at higher altitude compared to the main negative charge centre. The PBP/RS ratio (representing the intensity of the PBP) between Type 1 and Type 2 should probably also be noticeably different considering one PBP type occurs further away from the measuring antenna. However, our findings did not support this hypothesis. Our results showed that the PBP-RS separation for Type 2 is significantly higher than Type 1 and the PBP/RS ratio between the two PBP types is almost similar. The observation of Wu et al. [8] also did not support this hypothesis since their PBP-RS separations for both +PBP and $-\mathrm{PBP}$ are almost the same, and they speculated that the difference in initial polarities of $+\mathrm{PBP}$ and $-\mathrm{PBP}$ in positive ground flashes is caused by different directions of channel propagation.

According to Nag and Rakov [10], the basic tripolar structure of the thundercloud is not conducive to the production of positive lightning while [31] stated that the tripolar structure is more consistent with intracloud discharges, negative ground flashes, and air discharges, which are the dominant lightning types in isolated thunderclouds. In their study, Nag and Rakov [10] discussed six conceptual cloud charge configurations and scenarios that have been observed or hypothesized over the years and lead to the production of positive lightning. The cloud configurations are the tilted dipole, positive monopole, inverted dipole, unusually large lower positive charge region, negative in-cloud leader channel cut-off, and branching of in-cloud channel.

For the case of inverted dipole, the main positive and main negative charge regions were found at altitudes where, respectively, main negative and main positive charge would be found in normal-polarity storms [38]. In addition, previous researchers also found that there is a smaller negative charge region near the bottom of the cloud that serves to facilitate the positive ground flashes (as discussed by [10] and references therein). Same polarity PBP (Type 1) can be due to interaction between the main positive charge centre in the middle and the lower negative charge region while 
opposite polarity PBP (Type 2) can be due to interaction between the main negative charge centre at the top and the main positive charge centre. Considering that the inverted dipole has been suggested as the dominant charge structure during the dissipating stage of ordinary thunderstorms [39], and the presence of smaller negative charge region at the lower level that can trigger same polarity PBP (Type 1), this might explain why our percentage of same polarity PBP (Type 1) is higher than opposite polarity PBP (Type 2). The inverted dipole charge configuration would also explain why we have larger PBP-RS for opposite polarity PBP (Type 2) because the main negative centre now is located above the main positive centre.

According to Cooray and Scuka [29], opposite polarity PBP can take place between the main negative charge centre and the lower positive charge centre, similar to PBP in negative ground flashes but for the case of positive ground flashes, most of the charges in the negative charge centre are neutralized in neutralizing the lower positive charge. As a result, the vertical charge channel created is repolarized in the field of the main positive charge centre and serves to launch a positive leader towards the ground [6]. This would result in positive ground flashes with opposite polarity PBP.

For composite polarity PBP (Type 3), Gomes and Cooray [5] suggested that it may be viewed as the interaction between charge centres when the discharge channel is not vertical while Qie et al. [9] suggested that PBP trains with composite polarity could be due to breakdown discharges between both upper and lower charge layers. According to [40], the bi-directional, zero-net-charge leader concept of lightning development has become the major key in interpreting various physical processes in lightning. The essence of this concept, according to [40] is: lightning initiation in the electrified cloud occurs as a bi-directional, bi-polar, zero-net-charge leader and electrodeless discharge. In the bi-directional leader concept discussed in [3], a negatively charged channel initiated from the outer boundary of the negative charge centre, propagates downwards while the positively charged channel penetrates the negative charge centre. The same should also be true for the positive leader, initiated from the outer boundary of the positive charge centre, the positively charged channel propagates downwards while the negatively charged channel penetrates the positive charge centre. Electric field changes recorded during this bi-direction movement of the charges would result in the same polarity pulses when the channel is vertical. However, it was observed by previous researchers that the channel can be curved and not straight (as discussed by [5] and references therein). In cases where the channel is not vertical, pulses in the waveform would have mixed polarity, and this, we believe, is the reason for the composite polarity PBP (Type 3).

\section{Summary of Results}

Characteristics of the PBP in 51 positive ground flashes, based on remote electric field measurement during 2014 summer thunderstorms in Sweden have been presented and the results are summarized as follows:

(i) PBP trains were observed in $44(86 \%)$ of the cases while for the remaining seven $(14 \%)$ no PBP trains were detected.

(ii) From the 44 cases, multiple trains PBP were observed in seven (16\%) of the cases while $37(84 \%)$ were single train PBP.

(iii) Based on the initial polarity of the pulses, we identified three types of PBP. Of the PBP $48 \%$ have the same polarity as the first return stroke (Type 1), 34\% have the opposite polarity (Type 2) while the remaining $18 \%$ have composite polarity (Type 3 ).

(iv) Pulses in the PBP train are typically bipolar with the majority having a smooth initial rising portion. Some have several small pulses superimposed on the rising part while a few others have multiple peaks. The average ratios of the PBP peak to the first return stroke lie between 0.21 and 0.26 . One case of PBP, however, registered a peak value higher than the first return stroke.

(v) For Type 1, Type 2, and Type 3, the PBP-RS separations were found to be $75.1 \mathrm{~ms}, 114.6 \mathrm{~ms}$, and $59.2 \mathrm{~ms}$ while the pulse train durations were $5.9 \mathrm{~ms}, 2.6 \mathrm{~ms}$, and $24.8 \mathrm{~ms}$, respectively. Also, 
the interpulse durations were found to be $115.1 \mu \mathrm{s}, 93.7 \mu \mathrm{s}$, and $57.2 \mu \mathrm{s}$. For individual pulse duration, the average values for the first half cycle $\left(\mathrm{T}_{1}\right)$ were $8.2 \mu \mathrm{s}, 3.8 \mu \mathrm{s}$, and $4.9 \mu \mathrm{s}$ while for the second half cycle $\left(\mathrm{T}_{2}\right)$ the values were $10.0 \mu \mathrm{s}, 7.3 \mu \mathrm{s}$, and $8.3 \mu \mathrm{s}$. Total pulse durations $\left(\mathrm{T}_{1}+\mathrm{T}_{2}\right)$ were found to be $16.9 \mu \mathrm{s}, 10.0 \mu \mathrm{s}$, and $12.8 \mu \mathrm{s}$. These values were for Type 1 , Type 2 , and Type 3 respectively.

(vi) For multiple trains PBP $(N=7)$, six flashes have one subsequent PBP train while one flash has two subsequent PBP trains following the first PBP train.

(vii) Compared to the first PBP train, characteristics of the subsequent PBP trains $(N=8)$ were relatively smaller. The PBP peak amplitude relative to the return stroke peak, pulse train duration, individual pulse duration, and interpulse duration for the subsequent PBP trains were found to be $0.14,3.63 \mathrm{~ms}, 11.05 \mu \mathrm{s}$, and $43.78 \mu$ s respectively. Additionally, the time interval between the largest PBP and the first return stroke (PBP-RS separation) was found to be $73.23 \mathrm{~ms}$.

\section{Conclusions}

Based on the findings, we have come to several conclusions. First, the non-detection of PBP in some of the positive ground flashes could be due to a relatively small PBP amplitude below noise level and their occurrence outside the pre-trigger setting of the transient recorder. Second, the PBP in positive ground flashes during summer thunderstorms in Sweden are weak since the average ratios of the PBP peak to the first return stroke peak lie only between 0.21 and 0.26 . We also discussed possible reasons for the different types of PBP observed. Based on the conceptual charge cloud configuration discussed by Nag and Rakov [10], we found that the inverted dipole is consistent with our observation. The same polarity PBP (Type 1) could be due to the interaction between the main positive charge centre in the middle and the lower negative charge region while opposite polarity PBP (Type 2) could be due to the interaction between the main negative charge centre at the top and the main positive charge centre. We also believe that composite polarity PBP (Type 3) is due to the bi-directional leader process in a non-vertical channel.

Acknowledgments: The authors would like to express their gratitude to all the people who have directly or indirectly contribute towards the successful completion of this paper. Participation of Dalina Johari is funded by the Ministry of Education of Malaysia and Universiti Teknologi Mara Malaysia. Participations of Vernon Cooray and Mahbubur Rahman are funded by the fund from B. John F. and Svea Andersson donation at Uppsala University. Participation of Mohd Muzafar Ismail is funded by the Ministry of Education of Malaysia and Universiti Teknikal Malaysia Melaka. We would also like to thank Shri Ram Sharma from Tribhuvan University Kathmandu, Nepal for a fruitful discussion during his stay at Uppsala University. Also many thanks to Thomas Götschl for the assistance in the measurement setup and acquisition of lightning data from the Swedish LLS database. Finally, the authors would like to acknowledge the Division of Electricity, Ångström Laboratory, Uppsala University, for the excellent facility provided to carry out this research.

Author Contributions: The study was completed with cooperation from all authors. Dalina Johari as the first author prepared and carried out the measurements, collected the data, analyzed the data, and wrote the manuscript. Vernon Cooray had the idea and checked the validation of the measurements analysis. Mahbubur Rahman reviewed the manuscript. Pasan Hettiarachchi and Mohd Muzafar Ismail supported measurement technique and analysis. All authors agreed with the submission of the manuscript.

Conflicts of Interest: The authors declare no conflict of interest.

\section{References}

1. Rakov, V.A.; Uman, M.A. Positive and bipolar lightning discharges to ground. In Lightning: Physics and Effects; Cambridge University Press: Cambridge, UK, 2003; pp. 214-240.

2. Rakov, V.A.; Uman, M.A. Downward negative lightning discharges to ground. In Lightning: Physics and Effects; Cambridge University Press: Cambridge, UK, 2003; pp. 108-213.

3. Cooray, V. Mechanism of the lightning flash. In The Lightning Flash; Cooray, V., Ed.; The Institution of Engineering and Technology: London, UK, 2014; pp. 119-229.

4. Ushio, T.; Kawasaki, Z.-I.; Matsu-ura, K.; Wang, D. Electric fields of initial breakdown in positive ground flash. J. Geophys. Res. 1998, 103, 14135-14139. [CrossRef] 
5. Gomes, C.; Cooray, V. Radiation field pulses associated with the initiation of positive cloud to ground lightning flashes. J. Atmos. Sol. Terr. Phys. 2004, 66, 1047-1055. [CrossRef]

6. Zhang, Y.; Zhang, Y.; Lu, W.; Zheng, D. Analysis and comparison of initial breakdown pulses for positive cloud-to-ground flashes observed in Beijing and Guangzhou. Atmos. Res. 2013, 129-130, 34-41. [CrossRef]

7. Schumann, C.; Saba, M.M.F.; da Silva, R.B.G.; Schulz, W. Electric fields changes produced by positives cloud-to-ground lightning flashes. J. Atmos. Sol. Terr. Phys. 2013, 92, 37-42. [CrossRef]

8. Wu, T.; Takayanagi, Y.; Funaki, T.; Yoshida, S.; Ushio, T.; Kawasaki, Z.-I.; Morimoto, T.; Shimizu, M. Preliminary breakdown pulses of cloud-to-ground lightning in winter thunderstorms in Japan. J. Atmos. Sol. Terr. Phys. 2013, 102, 91-98. [CrossRef]

9. Qie, X.; Wang, Z.; Wang, D.; Liu, M. Characteristics of positive cloud-to-ground lightning in da Hinggan Ling forest region at relatively high latitude, northeastern China. J. Geophys. Res. Atmos. 2013, 118, 13393-13404. [CrossRef]

10. Nag, A.; Rakov, V.A. Positive lightning: An overview, new observations, and inferences. J. Geophys. Res. 2012, 117. [CrossRef]

11. Clarence, N.D.; Malan, D.J. Preliminary discharge processes in lightning flashes to ground. Q. J. R. Meteorol. Soc. 1957, 83, 161-172. [CrossRef]

12. Brook, M. Breakdown electric fields in winter storms. Res. Lett. Atmos. Electr. 1992, 12, 47-52.

13. Gomes, C.; Cooray, V.; Jayaratne, C. Comparison of preliminary breakdown pulses observed in Sweden and in Sri Lanka. J. Atmos. Sol. Terr. Phys. 1998, 60, 975-979. [CrossRef]

14. Nag, A.; Rakov, V.A. Electric field pulse trains occurring prior to the first stroke in negative cloud-to-ground lightning. IEEE Trans. Electromagn. Compat. 2009, 51, 147-150. [CrossRef]

15. Baharudin, Z.A.; Ahmad, N.A.; Fernando, M.; Cooray, V.; Mäkelä, J.S. Comparative study on preliminary breakdown pulse trains observed in Johor, Malaysia and Florida, USA. Atmos. Res. 2012, 117, 111-121. [CrossRef]

16. Baharudin, Z.A.; Fernando, M.; Ahmad, N.A.; Mäkelä, J.S.; Rahman, M.; Cooray, V. Electric field changes generated by the preliminary breakdown for the negative cloud-to-ground lightning flashes in Malaysia and Sweden. J. Atmos. Sol. Terr. Phys. 2012, 84-85, 15-24. [CrossRef]

17. Marshall, T.; Schulz, W.; Karunarathna, N.; Karunarathne, S.; Stolzenburg, M.; Vergeiner, C.; Warner, T. On the percentage of lightning flashes that begin with initial breakdown pulses. J. Geophys. Res. Atmos. 2014, 119, 445-460. [CrossRef]

18. Weidman, C.D.; Krider, E.P. The radiation field wave forms produced by intracloud lightning discharge processes. J. Geophys. Res. 1979, 84, 3159-3164. [CrossRef]

19. Bils, J.R.; Thomson, E.M.; Uman, A. Electric field pulses in close lightning cloud flashes. J. Geophys. Res. 1988, 93, 15933-15940. [CrossRef]

20. Villanueva, Y.; Rakov, V.A.; Uman, M.A.; Brook, M. Microsecond-scale electric field pulses in cloud lightning discharges. J. Geophys. Res. 1994, 99, 14353-14360. [CrossRef]

21. Sharma, S.R.; Fernando, M.; Gomes, C. Signatures of electric field pulses generated by cloud flashes. J. Atmos. Sol. Terr. Phys. 2005, 67, 413-422. [CrossRef]

22. Stolzenburg, M.; Marshall, T.C.; Karunarathne, S.; Karunarathna, N.; Vickers, L.E.; Warner, T.A.; Orville, R.E.; Betz, H.D. Luminosity of initial breakdown in lightning. J. Geophys. Res. Atmos. 2013, 118, 2918-2937. [CrossRef]

23. Stolzenburg, M.; Marshall, T.C.; Karunarathne, S.; Karunarathna, N.; Orville, R.E. Leader observations during the initial breakdown stage of a lightning flash. J. Geophys. Res. Atmos. 2014, 119, 12198-12221. [CrossRef]

24. Campos, L.Z.S.; Saba, M.M.F. Visible channel development during the initial breakdown of a natural negative cloud-to-ground flash. Geophys. Res. Lett. 2013, 40, 4756-4761. [CrossRef]

25. Karunarathne, S.; Marshall, T.C.; Stolzenburg, M.; Karunarathna, N.; Vickers, L.E.; Warner, T.A.; Orville, R.E. Locating initial breakdown pulses using electric field change network. J. Geophys. Res. Atmos. 2013, 118, 7129-7141. [CrossRef]

26. Bitzer, P.M.; Christian, H.J.; Stewart, M.; Burchfield, J.; Podgorny, S.; Corredor, D.; Hall, J.; Kuznetsov, E.; Franklin, V. Characterization and applications of VLF/LF source locations from lightning using the Huntsville Alabama Marx Meter Array. J. Geophys. Res. Atmos. 2013, 118, 3120-3138. [CrossRef] 
27. Wu, T.; Yoshida, S.; Akiyama, Y.; Stock, M.; Ushio, T.; Kawasaki, Z. Preliminary breakdown of intracloud lightning: Initiation altitude, propagation speed, pulse train characteristics, and step length estimation. J. Geophys. Res. Atmos. 2015, 120, 9071-9086. [CrossRef]

28. Nag, A.; Rakov, V.A. Pulse trains that are characteristic of preliminary breakdown in cloud-to-ground lightning but are not followed by return stroke pulses. J. Geophys. Res. Atmos. 2008, 113. [CrossRef]

29. Cooray, V.; Scuka, V. What attracts a lightning flash to ground? In Proceedings of the 10th International Conference on Atmospheric Electricity, Osaka, Japan, 10-14 June 1996; pp. 256-259.

30. Levine, D.M. Sources of the strongest RF radiation from lightning. J. Geophys. Res. 1980, 85, 4091-4095. [CrossRef]

31. Williams, E. Charge structure and geographical variation of thunderclouds. In The Lightning Flash; Cooray, V., Ed.; The Institution of Engineering and Technology: London, UK, 2014; pp. 1-14.

32. Galvan, A.; Fernando, M. Operative Characteristics of a Parallel-Plate Antenna to Measure Vertical Electric Fields from Lightning Fields from Lightning Flashes; Report UURIE 285-00; Uppsala University: Uppsala, Sweden, 2000.

33. Sonnadara, U.; Kathriarachchi, V.; Cooray, V.; Montano, R.; Götschl, T. Performance of lightning locating systems in extracting lightning flash characteristics. J. Atmos. Sol. Terr. Phys. 2014, 112, 31-37. [CrossRef]

34. Sonnadara, U.; Cooray, V.; Götschl, T. Characteristics of cloud-to-ground lightning flashes over Sweden. Phys. Scr. 2006, 74, 541-548. [CrossRef]

35. Fuquay, D.M. Positive cloud-to-ground lightning in summer thunderstorms. J. Geophys. Res. Ocean. 1982, 87, 7131-7140. [CrossRef]

36. Cooray, V. Electromagnetic Fields of Lightning Flashes. In An Introduction to Lightning; Springer: Dordrecht, The Netherlands, 2015; pp. 135-165.

37. Rust, W.D.; MacGorman, D.R.; Arnold, R.T. Positive cloud to ground lightning flashes in severe storms. Geophys. Res. Lett. 1981, 8, 791-794. [CrossRef]

38. Rust, W.D.; MacGorman, D.R.; Bruning, E.C.; Weiss, S.A.; Krehbiel, P.R.; Thomas, R.J.; Rison, W.; Hamlin, T.; Harlin, J. Inverted-polarity electrical structures in thunderstorms in the Severe Thunderstorm Electrification and Precipitation Study (STEPS). Atmos. Res. 2005, 76, 247-271. [CrossRef]

39. Williams, E.; Yair, Y. The microphysical and electrical properties of sprite-producing thunderstorms. 2006, 225, 57-83.

40. Mazur, V. Physical processes during development of lightning flashes. C. R. Phys. 2002, 3, $1393-1409$. [CrossRef] 